\title{
Disproportionate abdominal visceral fat mass reduction and complete reversal of cardiovascular remodelling accompany Roux-en-Y gastric bypass but not gastric banding - benefits beyond simply weight loss
}

\author{
Jennifer J Rayner ${ }^{1 *}$, Rajarshi Banerjee ${ }^{1}$, Jane M Francis ${ }^{1}$, Ravi $\vee$ Shah $^{2}$, Venkatesh L Murthy ${ }^{4}$, James Byrne ${ }^{3}$, \\ Stefan Neubauer ${ }^{1}$, Oliver Rider ${ }^{1}$ \\ From 19th Annual SCMR Scientific Sessions \\ Los Angeles, CA, USA. 27-30 January 2016
}

\section{Background}

It is emerging that distribution of body fat, and in particular visceral fat (VFAT) is more important in determining cardiovascular risk than total body fat percentage. Rouxen-Y gastric bypass (RYGB) may preferentially reduce visceral fat, thus providing a mechanism to study the impact of visceral fat on cardiovascular function. We sought to determine 1) whether visceral fat is related to adverse left ventricular (LV) remodelling and reduced aortic distensibility, and 2) whether RYGB, by preferentially targeting visceral fat, results in greater improvements in LV geometry and vascular function than gastric banding.

\section{Methods}

159 subjects (body mass index (BMI) 18.5-59.2) without cardiovascular risk factors, underwent dual-energy X-Ray absorptiometry for fat distribution, MRI assessment (1.5T) for visceral fat and cardiac MR for LV geometry (mass and mass:volume ratio (LVMVR)). Aortic distensibility was assessed at 3 levels; the ascending and proximal descending aorta at pulmonary artery level and the abdominal aorta. 26 subjects underwent repeat testing 2.5 years following bariatric surgery (14 RYGB and 12 gastric banding).

\section{Results}

After matching for BMI and total fat mass, patients were separated into two groups according to visceral fat. The high visceral fat group had greater concentric LV remodelling (LVMVR $0.93 \pm 0.02$ vs $0.77 \pm 0.02$; $\mathrm{p}<0.001$ ) and reduced aortic distensibility (by 18 $27 \% ; \mathrm{p}<0.01$ ), suggesting that visceral fat rather than total fat mass is related to adverse cardiovascular remodelling.

2.5 years after bariatric surgery, both groups had lost significant amounts of weight with BMI $32.7 \pm 1.2 \mathrm{~kg} /$ $\mathrm{m}^{2}$ after RYGB and $32.6 \pm 1.6 \mathrm{~kg} / \mathrm{m}^{2}$ after gastric band $(\mathrm{p}=0.94)$. Compared to gastric banding, RYGB resulted in greater reduction in visceral fat $(62 \pm 3 \%$ vs $31 \pm 6 \%$ fall; $\mathrm{p}<0.001$, Figure 1 ) despite similar total fat mass loss $(41 \pm 3 \%$ vs $33 \pm 5 \% ; \mathrm{p}=0.92)$. Associated with visceral fat loss was greater regression of LV mass $(23 \%$ vs $14 \%$ fall; p $=0.05)$ and greater improvement in aortic distensibility (95\% vs $37 \%$; $\mathrm{p}=$ 0.05). Importantly, following RYGB, visceral fat levels were both lower than in matched obese controls who had not undergone surgery $(\mathrm{n}=36$; VFAT post RYGB $66.5 \pm 8.9 \mathrm{~cm}^{2}$ vs $\left.125.2 \pm 8.9 \mathrm{~cm}^{2} ; \mathrm{p}<0.05\right)$, and similar to normal weight controls $(\mathrm{n}=73$; VFAT $66.5 \pm 8.9$ $\mathrm{cm}^{2}$ post RYGB vs $48.2 \pm 3.5 \mathrm{~cm}^{2}$; $\left.\mathrm{p}>0.05\right)$. Despite remaining obese post RYGB, LV mass and aortic distensibility were not different from normal weight controls (LV post RYGB $102.6 \pm 5.0 \mathrm{~g}$ vs $103.1 \pm 3.4 \mathrm{~g}$; aortic distensibility post RYGB $8.54 \pm 0.74 \mathrm{mmHg}^{-1}$ vs $7.97 \pm 0.33 \mathrm{mmHg}^{-1}$; both $\left.\mathrm{p}>0.05\right)$.

${ }^{1}$ University of Oxford, Oxford, UK

Full list of author information is available at the end of the article 


\section{A}

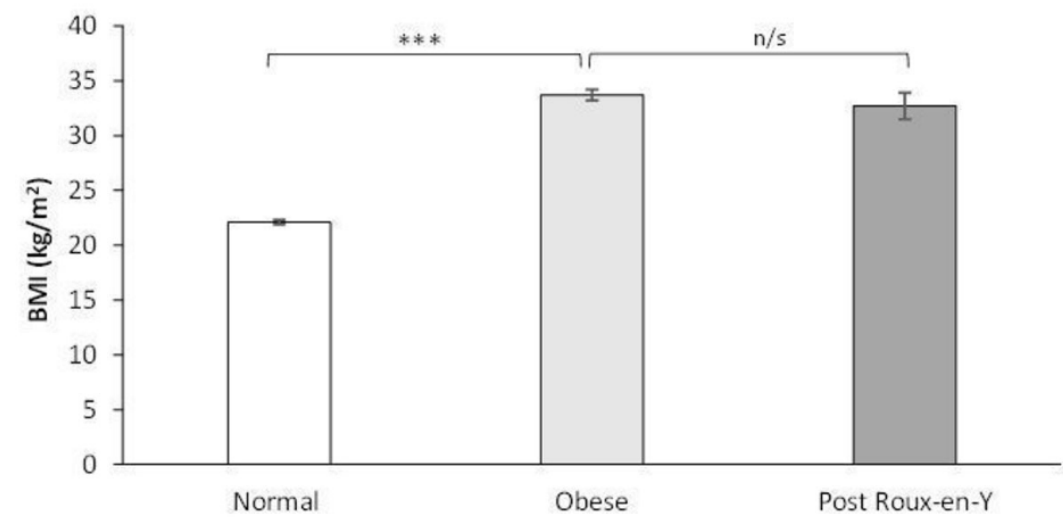

\section{B}

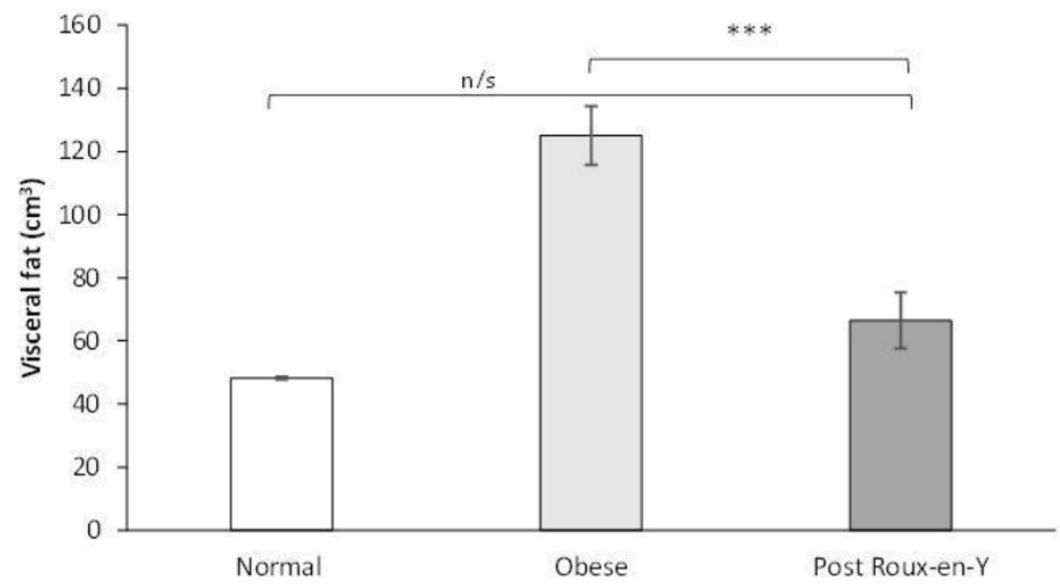

C

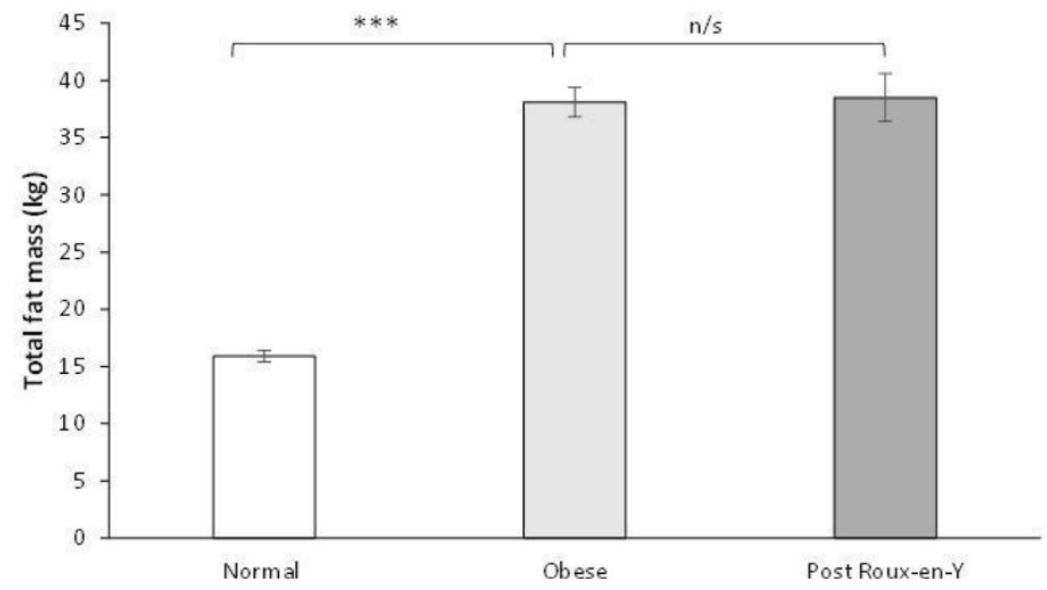

Figure 1 Despite BMI and total fat mass post RYGB remaining in the obese range ( $A$ and $B$ ), visceral fat is the same as individuals with normal BMI (C) (data represents mean values with SE bars; $n / s$ indicates non-significant; ${ }^{* * *}$ indicates $p<0.001$ ). 

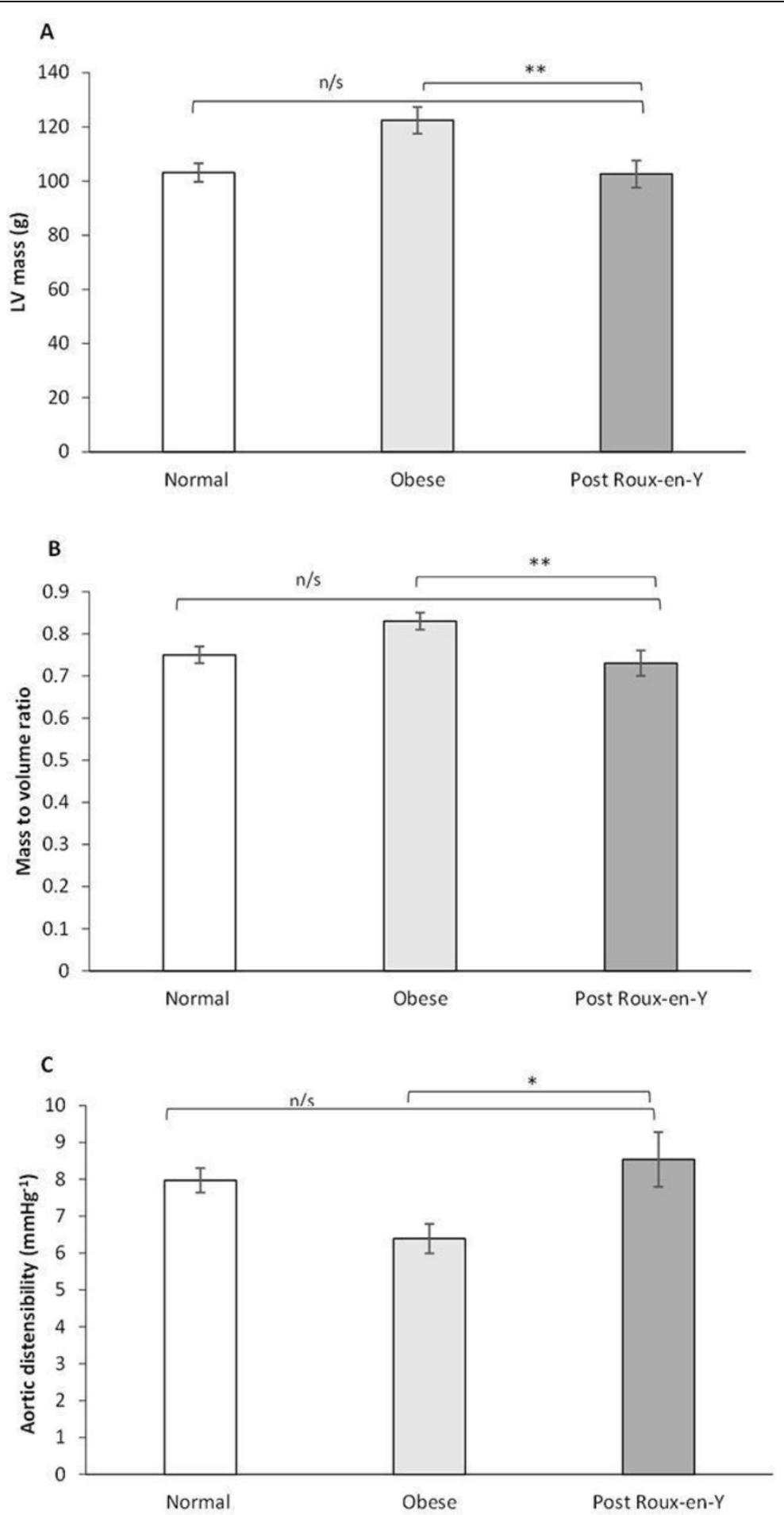

Figure 2 Left ventricular mass (A), and mass-to-volume ratio (B), as well as aortic distensibility in the descending aorta (C) return to values not significantly different from normal post RYGB (data represents mean values with SE bars; $\mathrm{n} / \mathrm{s}$ indicates non-significant; ${ }^{* *}$ indicates $p<0.05 ;^{* *}$ indicates $p<0.01{ }^{* * *}$ indicates $p<0.001$ ). 


\title{
Conclusions
}

When matched for BMI and total fat mass, high visceral fat is related to concentric LV remodelling and aortic stiffness. RYGB is more effective than gastric banding at reducing visceral fat, reversing concentric LV remodelling and reducing aortic stiffness. This strongly suggests that targeted visceral fat reduction with RYGB should be considered to treat cardiovascular remodelling in obesity.

\section{Authors' details}

${ }^{1}$ University of Oxford, Oxford, UK. ${ }^{2}$ Beth Israel Deaconess Medical Centre, Boston, MA, USA. ${ }^{3}$ University Hospital, Southampton, UK. ${ }^{4}$ University of Michigan, Ann Arbor, MI, USA.

Published: 27 January 2016

\begin{abstract}
doi:10.1186/1532-429X-18-S1-0135
Cite this article as: Rayner et al.: Disproportionate abdominal visceral fat mass reduction and complete reversal of cardiovascular remodelling accompany Roux-en- $Y$ gastric bypass but not gastric banding - benefits beyond simply weight loss. Journal of Cardiovascular Magnetic Resonance
\end{abstract} 2016 18(Suppl 1):0135.

Submit your next manuscript to BioMed Central and take full advantage of:

- Convenient online submission

- Thorough peer review

- No space constraints or color figure charges

- Immediate publication on acceptance

- Inclusion in PubMed, CAS, Scopus and Google Scholar

- Research which is freely available for redistribution

Submit your manuscript at www.biomedcentral.com/submit
C Biomed Central 